\title{
Use of miltefosine to treat canine visceral leishmaniasis caused by Leishmania infantum in Brazil
}

\author{
Fabio dos Santos Nogueira', Valdir Carlos Avino², Fredy Galvis-Ovallos ${ }^{3}$, Vera Lucia Pereira-Chioccola ${ }^{4}$, \\ Marcio Antonio Batistella Moreira ${ }^{5}$, Ana Paula Peres Lopes Romariz ${ }^{1}$, Leticia M. Molla ${ }^{2}$ and Ingrid Menz ${ }^{6^{*}}$
}

\begin{abstract}
Background: Visceral leishmaniasis $(\mathrm{VL})$ is an infectious disease with a variety of clinical signs. The main form of parasite transmission to humans and other mammalian hosts is through the bite of infected arthropod females with Lutzomyia longipalpis serving as the main vector in the Americas. Dogs are the main urban domestic reservoirs of the parasite and the main source of vector infection due to their high prevalence in endemic areas and the large number of parasites in the skin of infected animals. Although miltefosine has been used in Europe since 2002 for treatment of VL infected dogs, in the Americas the treatment of dogs has not been recommended. Therefore, this study aimed to evaluate efficacy of miltefosine observing a reduction of clinical signs in infected dogs and the infectiveness to the vector by Leishmania (L.) infantum.

Methods: To our knowledge, this is the first controlled study using qPCR and xenodiagnosis to evaluate the efficacy of miltefosine (Milteforan ${ }^{\circledast}$, Virbac) as a single treatment in Brazil. Thirty-five adult dogs with canine visceral leishmaniasis (CVL), confirmed by clinical and laboratory tests, were included in this study. They received miltefosine at a dose of $2 \mathrm{mg} / \mathrm{kg}$ every $24 \mathrm{~h}$ for 28 days. The dogs were observed over a three-month period, during which clinical evaluations based on a scoring system were conducted at pre-established times. Parasite load was assessed by cytology and real-time polymerase chain reaction ( $(\mathrm{PCR})$. Transmissibility to the vector was evaluated by xenodiagnosis.
\end{abstract}

Results: At the end of the period, the following were observed: (i) the remission of clinical signs with a reduction in clinical scores for $94.2 \%$ of the animals; (ii) a statistically significant reduction (98.7\%) in parasitic load by qPCR; and (iii) a reduction in infectivity to sand flies. After treatment, $74.2 \%$ of the animals remained or had become non-infectious.

Conclusions: Our study indicates that the use of miltefosine administered orally for 4 weeks contributes to a clinical improvement and reduction in infectivity of dogs to $L$. infantum.

Keywords: Canine visceral leishmaniasis, Miltefosine, Clinical signs, qPCR, Infectiveness, Xenodiagnosis, Treatment

\section{Background}

Visceral leishmaniasis (VL) is an infectious, non-contagious, chronic disease with significant clinical and epidemiological control priority in the world. In the last few decades, epidemiological changes in VL, including increases in incidence and lethality rate and its spread to new and even urban areas, have been observed [1-5].

\footnotetext{
* Correspondence: menzingrid@yahoo.com.br

${ }^{6}$ Ingrid Menz Self-employed Veterinarian, São Paulo, Campinas, Brazil Full list of author information is available at the end of the article
}

Leishmania (Leishmania) infantum is the aethiological agent of canine visceral leishmaniasis (CVL) distributed in the Old and New World. The main form of transmission of the parasite to humans and other mammalian hosts is through the bite of infected sand flies (Diptera: Psychodidae). In Brazil, the species involved in the transmission are mainly Lu. longipalpis and Lu. cruzi. Unlike in European countries, where there are two well-defined transmission seasons, in Brazil, in the areas with an occurrence of Lutzomyia longipalpis, this vector can be

(c) The Author(s). 2019 Open Access This article is distributed under the terms of the Creative Commons Attribution 4.0 International License (http://creativecommons.org/licenses/by/4.0/), which permits unrestricted use, distribution, and 
found throughout the entire year. In general, the population density of sand flies increases with high temperature and high relative humidity, resulting in periods of high risk of transmission of the parasite.

Phlebotomine infection occurs when females bite an infected host, thereby ingesting amastigotes. These amastigotes undergo successive divisions and are progressively transformed into infectious metacyclic promastigotes, which are regurgitated in the skin of mammalian hosts during a new blood meal [6-8].

CVL diagnosis has been challenging for public health professionals due to the existence of asymptomatic dogs, the high variability of clinical signs and the difficulty of achieving a diagnostic with high sensitivity and specificity. However, new methods based on DNA sequencing are being applied to parasite diagnosis. The use of real-time PCR (qPCR) has expanded over the past decades, since it is possible to detect parasite DNA in infected animals regardless of their clinical status. In addition, qPCR is able to quantify parasitic load and monitor follow-up treatment [9].

Xenodiagnosis is a useful method for the identification and isolation of parasites in their natural arthropod vectors, or for identification of the infectiveness of the infected host $[10,11]$. This method has been used to evaluate the infectivity of $\mathrm{Lu}$. longipalpis females which fed on naturally or experimentally infected dogs and the association between this infectivity and host symptoms [12-15].

Different treatment protocols have shown that parasitic forms in the skin and lymphoid organs of dogs are significantly reduced after treatment. Since most of these treated animals continue to be reservoirs, and consequently a source of infection, their monitoring is of extreme importance [3, 16-18].

Miltefosine (hexadecilfosfocoline) was originally studied and classified as an anti-tumor drug [19] and its leishmanicide potential was identified in the 1980s. Its compound is the first oral anti-Leishmania drug, which was studied in partnership with the World Health Organization (WHO) and registered as efficient for treatment of infections caused by $L$. $(L$.) donovani in humans [20,21]. Miltefosine inhibits the biosynthesis of the glycosyl phosphatidyl inositol (GPI) receptor, the key molecule for Leishmania intracellular survival. It also interferes with the synthesis of phospholipase and protein kinase $\mathrm{C}$, which are Leishmania-specific. The metabolic action of this compound can affect the biosynthesis of glycolipids and membrane glycoproteins of the parasite, causing apoptosis. Other studies suggest that this drug has immunomodulatory properties [22-25].

In 2007, Virbac Laboratories launched miltefosine on the European veterinary market as Milteforan for the purpose of treating dogs with CVL. According to
Gradoni et al. [26], treatment of asymptomatic and oligosymptomatic dogs results in high rates of recovery and avoidance of the development of clinical disease. According to the WHO [27], the reduction of cutaneous parasitism and clinical signs, and the recovery of cellular immune response, could reduce the capacity to infect sand flies, consequently reducing the prevalence of the disease in canines and humans in endemic areas $[11,26,28,29]$. Based on these data, the present study aimed to evaluate the efficacy of miltefosine in reducing clinical signs in naturally infected dogs and the infectivity to sand flies.

\section{Methods}

\section{Dog housing conditions}

This study was conducted in Andradina, located in the northwestern region of the state of São Paulo, Brazil, an area endemic for VL with canine and human transmission [27]. Dogs were maintained in a $45 \mathrm{~m}^{2}$ kennel with an antechamber. The kennels were completely protected with a $1 \mathrm{~mm}$ mesh tissue screen to prevent sand fly access. As a vector surveillance measure, a CDC light trap was installed and turned on daily between 17:00 and 06:00 h. Video cameras were used to monitor the kennels for the occurrence of dog fights and accidents.

\section{Dogs}

For this study 35 adult dogs (18 males and 17 females), weighing between 4-24 $\mathrm{kg}$ and of different breeds (2 Dachshunds, 2 Poodles, 3 Brazilian Terriers, 1 Cocker Spaniel and 27 mixed breeds), were selected. All dogs had previously been naturally infected by $L$. $(L$.) infantum. CVL was determined by clinical, serological and molecular diagnoses. All dogs were neutered, spayed, and fed with a balanced commercial dog food ad libitum. They were kept inside a screened kennel and were microchipped with Virbac Backhome ${ }^{\bullet}$ microchips and then photographed with their microchip numbers.

\section{Inclusion, exclusion and efficacy criteria}

Dogs showing clinical signs characteristic of CVL and with infection status proven by serological, parasitological and/or molecular diagnosis were selected to start the therapy. Serology was performed using the ELISA method and the immunochromatographic DPP test at Instituto Adolfo Lutz in São Paulo, Brazil. All dogs were positive for $L$. (L.) infantum (ELISA cut-off $=0.174$ ).

Dogs with significant alterations in renal and/or hepatic function or with other infectious diseases were excluded.

Efficacy criteria were determined by reduction in clinical scores $[18,30,31]$, in decreasing of parasite DNA and infectiveness to sand flies. The score was defined according to the severity of each clinical sign and 
the final value was obtained from the sum of all the values. Quantitative parasite load was estimated through qPCR and the transmissibility of parasites to sand flies was evaluated through xenodiagnosis.

\section{Sample size}

The sample size was determined by using a confidence interval of 95\%, aiming for results similar to those found in a study conducted by Virbac in France [Study code: F-107.010000-60003], which showed a treatment success rate of $82.7 \%$ and a variability of $70-96 \%$. Thus, the minimum number of dogs was 32 . Thirty-five animals were initially selected, taking into account possible losses by mortality or fights. The number of dogs requested for this study was obtained according to the following equation (Lwanga \& Lemeshow [32]):

$$
n=\frac{\left\{[z(\text { alpha })]^{2} \times p \times(1-p)\right\}}{d^{2}}
$$

where $n$ is the sample size; $z$ (alpha) is the value obtained through the normal distribution to obtain a confidence interval of $95 \%: z$ (alpha $)=1.96 \%$; $\mathrm{p}$ is the expected ratio; and $d$ is the accuracy of estimate $(\mathrm{d}=$ range size/2).

\section{Experimental design}

The dogs were treated orally with miltefosine (Milteforan ${ }^{\circ}$, Virbac) $2 \mathrm{mg} / \mathrm{kg}$ body weight, for four weeks (W0-W3). After each administration, the dogs were observed for $1 \mathrm{~h}$ to monitor for vomiting and/or regurgitation to ensure complete absorption of the drug. Animal weight, infection status (serological, cytological and parasite load-qPCR) and infectivity to sand flies (xenodiagnosis) were evaluated before treatment at week 0 (W0). Dog weight and clinical status were evaluated every two weeks from the beginning of treatment, through W12. Serological, cytological and parasite load-qPCR were evaluated at W6 and W12. Infectivity to sand flies was evaluated again at W12.

\section{Clinical evaluation}

The dogs were weighed and given routine physical examinations immediately before beginning therapy and at 14-day intervals. The same researcher conducted all clinical evaluations in a minimum observation time of 20 min per dog to maintain consistency.

Clinical scores [30] were classified according to the severity of clinical signs as shown in Table 1.

\section{Skin qPCR}

Skin fragments obtained from the ear pinna, collected at the same site immediately after xenodiagnosis, were analysed for quantification of parasitic load. Prior to
DNA extraction, the skin samples were digested in a lysis buffer $(10 \mathrm{mM}$ Tris- $\mathrm{HCl}, \mathrm{pH}$ 8.0; $10 \mathrm{mM}$ EDTA, $0.5 \%$ SDS; $0.01 \% \mathrm{~N}$-laurilsarcozil and $100 \mathrm{~g} / \mathrm{ml}$ proteinase $\mathrm{K}$ ) and then incubated in a water bath at $56{ }^{\circ} \mathrm{C}$ for 2-18 h until complete tissue lysis had occurred [33]. The DNA molecules were extracted using a QIAamp DNA Mini Kit (Qiagen, Venlo, Netherland) according to the manufacturer's instructions and in equipment specifically used for DNA purification (a QIAcube robotic workstation, Qiagen). The concentrations and purity of DNA molecules were determined by the optical density (OD) ratio at $260 / 280 \mathrm{~nm}$ in a NanoDrop ND1000 (Thermo Scientific, Waltham, USA). qPCR had been previously standardized at the Instituto Adolfo Lutz (São Paulo) using serial dilutions of DNA extracted from reference strain cultures of $L$. (L.) infantum (MHOM/BR/ 1972/LD) [34]. The set of molecular markers used in the qPCR was LinJ31, sense and reverse (5'-CCG CGT GCC TGT CG-3' and 5'-CCC ACA CAA GCG GGA ACT-3'), and a TaqMan probe MGB (5'-CCT CCT TGG ACT TTG C-3'), marked with FAM (region 5 ') and with NFQ (region 3') [35]. The quality of the extracted DNA was confirmed by amplification of the canine

Table 1 Clinical scores used to evaluate variables before and after treatment

\begin{tabular}{|c|c|c|c|c|}
\hline \multirow[t]{2}{*}{ Clinical signs } & \multicolumn{4}{|c|}{ Intensity (scores) } \\
\hline & $\overline{0}$ & 1 & 2 & 3 \\
\hline Anorexia & $A$ & $P$ & & \\
\hline Polyuria/polydipsia & A & $P$ & & \\
\hline Epistaxis & A & $P$ & & \\
\hline Splenomegaly & $A$ & $P$ & & \\
\hline Vomiting & A & $P$ & & \\
\hline Digestive disorders & A & $P$ & & \\
\hline Uveitis & $A$ & $P$ & & \\
\hline Keratitis & A & $P$ & & \\
\hline Arthritis/limping & $A$ & $P$ & & \\
\hline Onychogryphosis & A & M & 1 & \\
\hline Weight loss & A & M & 1 & \\
\hline Conjunctivitis & $A$ & M & 1 & $\mathrm{~S}$ \\
\hline Blepharitis & $A$ & M & 1 & $S$ \\
\hline Lymphadenomegaly & A & M & 1 & $\mathrm{~S}$ \\
\hline Ulcers & A & M & I & $\mathrm{S}$ \\
\hline Nodules & A & M & I & $S$ \\
\hline Peeling & $A$ & M & 1 & $\mathrm{~S}$ \\
\hline Depigmentation & A & M & 1 & $S$ \\
\hline Hyperpigmentation & A & M & I & $\mathrm{S}$ \\
\hline Hyperkeratosis (feet) & A & M & I & $S$ \\
\hline Hyperkeratosis and/or Ulcers in nasal region & A & M & I & $\mathrm{S}$ \\
\hline
\end{tabular}

Abbreviations: $A$ absent, $P$ present, $M$ moderate, $I$ intense, $S$ severe 
gene glyceraldehyde-3-phosphate dehydrogenase, spermatogenicto (GAPDHS; GenBank: XM_533693.2) (Applied Biosystems, Waltham, USA), which was used as an internal control gene. The reactions were conducted with a final volume of $20 \mu \mathrm{l}$. The canine samples $(3 \mu \mathrm{l}$ of $100 \mathrm{ng} / \mu \mathrm{l})$ or DNA control $(50 \mathrm{ng}$ ) were added to a mixture of $10 \mu \mathrm{l}$ of $2 \times$ TaqMan Universal PCR Master Mix and $1 \mu \mathrm{l}$ of the molecular marker mix $(18 \mu \mathrm{M}$ of sense and reverse molecular markers and $5 \mu \mathrm{M}$ of TaqMan probe). The amplifications were conducted using an Applied Biosystems 7500 Real-time PCR, using a thermal cycle including $2 \mathrm{~min}$ at $50{ }^{\circ} \mathrm{C}$ and $10 \mathrm{~min}$ at $95{ }^{\circ} \mathrm{C}$, followed by 40 cycles of $95{ }^{\circ} \mathrm{C}$ for $15 \mathrm{~s}$ and $60{ }^{\circ} \mathrm{C}$ for $1 \mathrm{~min}$. Each DNA extraction set also included a negative tissue sample for Leishmania spp. together with the unknown sample in order to monitor cross-contamination during extraction. In each PCR run, a blank control consisting of DNA-free water plus PCR mix was used as blank control. Separate rooms were used for (i) DNA extraction; (ii) PCR mix and primer preparation; and (iii) addition of DNA from clinical samples (in duplicate) and positive control [34].

The results were based on a standard curve where known concentrations of parasites were used to perform the qPCR [34]. The curve had been constructed using seven different DNA concentrations (in triplicate) extracted from $L$. (L.) infantum $\left(1 \times 10^{7}\right.$ to $1 \times 10^{-1}$ promastigotes). The cycle threshold $\left(C_{t}\right)$ values were plotted on a graph (average of triplicates) versus the concentrations of DNA to determine the limit of detection of molecular marker LinJ31.

Parasite concentrations (number of amplified copies/3 $\mu$ l DNA sample) were calculated using the linear regression equation [36]

$$
y=a x+b
$$

where $y$ is $C_{t}$ ); $a$ is the slope of the curve; $x$ is the number of parasites; and $b$ is the detection limit, where the curve crosses the y-axis (y-intercept). The detection limit of LinJ31 for L. (L.) infantum was at $C_{t}$ of 37.75 with R2 of 0.9957. Then the number of amplified copies/ $3 \mu \mathrm{l}$ DNA sample was $\log _{10}$-transformed.

\section{Xenodiagnosis}

To avoid repelling or killing the sand flies, no topical and/or oral treatment against ectoparasites were applied before or during the study. After clinical evaluation, the dogs were sedated intramuscularly with acepromazine $1 \%$ (Acepram, Vetnil), $0.22 \mathrm{mg} / \mathrm{kg}$ and anesthetized intravenously with tiletamine and zolazepam (Zoletil ${ }^{\circ} 50$, Virbac), $0.12 \mathrm{ml} / \mathrm{kg}$ and transferred to the xenodiagnosis room. The sand fly feeding was conducted in the right internal ear of each dog, and a skin fragment from the same ear was collected for qPCR. This procedure was carried out using a $4 \mathrm{~mm}$ diameter "punch" (Dermatological Sterile Disposable Punch, Kolplast, Paulinia, Brazil), sterile surgical anatomical tweezers, a scalpel blade, a needle holder and mononylon thread. The fragments were immediately placed in $1.5 \mathrm{ml}$ tubes (Eppendorf PCR Tubes, Eppendorf ${ }^{\circ}$ São Paulo, Brazil) with saline solution $0.9 \%$ for the qPCR procedure.

Lutzomyia longipalpis females used for the xenodiagnosis were from a closed colony kept in the Departamento de Parasitologia of the Universidade Federal de Minas Gerais (UFMG). For transport to the isolated kennel, the insects were maintained in a container designed by da Costa-Val et al. [14] consisting of a transparent box $10 \mathrm{~cm}$ high by $8.7 \mathrm{~cm}$ in diameter, covered with a nylon screen lid, $10 \mathrm{~cm}$ in diameter, 80 rows per $\mathrm{cm}^{2}$, fastened to the outer edges of the box with silicon glue (Fig. 1a). Cotton moistened with water and sucrose $10 \%$ was placed on top of the screen lid to feed the insects during transport. The "phlebocontainers", each with 60 to 75 sand flies of which $70 \%$ were females, were carefully placed in styrofoam boxes with moistened paper to preserve humidity at $70-80 \%$ and transported to the location of the experiment. Due to the aggregated feeding behavior of this species, male insects $(30 \%)$ were included to stimulate the females during their feeding on the dogs. After transport, the "phlebocontainers" were evaluated for viability of the insects and taken to the xenodiagnosis room to be maintained at an ideal temperature (between $25-28{ }^{\circ} \mathrm{C}$ ) and humidity levels for $24 \mathrm{~h}$. A container was then placed over one of each dog's ears, covered with a black cloth, and left in place for $60 \mathrm{~min}$ to expose the ear to the sand flies. After exposure the insects were released into individual cages $(30 \times 30 \mathrm{~cm})$ of the same $1 \mathrm{~mm}$ mesh tissue screen, coded with the animal's microchip number, for stabilization of the peritrophic membrane and maintenance until dissection of the females. A cotton wad soaked with sucrose $10 \%$ solution was placed on each cage for 6 days. After this period, the sand flies were anesthetized with ether, transferred to small flasks, and taken to the clinical laboratory for dissection. Parasite count was undertaken as described by Diniz et al. [37]. The number of infected and uninfected females was determined from the total number of dissected females per dog. Information was obtained on the different sites in the gut where the parasites were found. After defecation, the females were dissected and evaluated to detect $L$. infantum promastigotes under an optical microscope at 400× (Zeiss ${ }^{\circ}$ Cx40, Jena, Germany). The dogs were considered infective if at least one parasite was found in the sand fly. Details about the stages of xenodiagnosis are presented in Fig. 1b-j. 

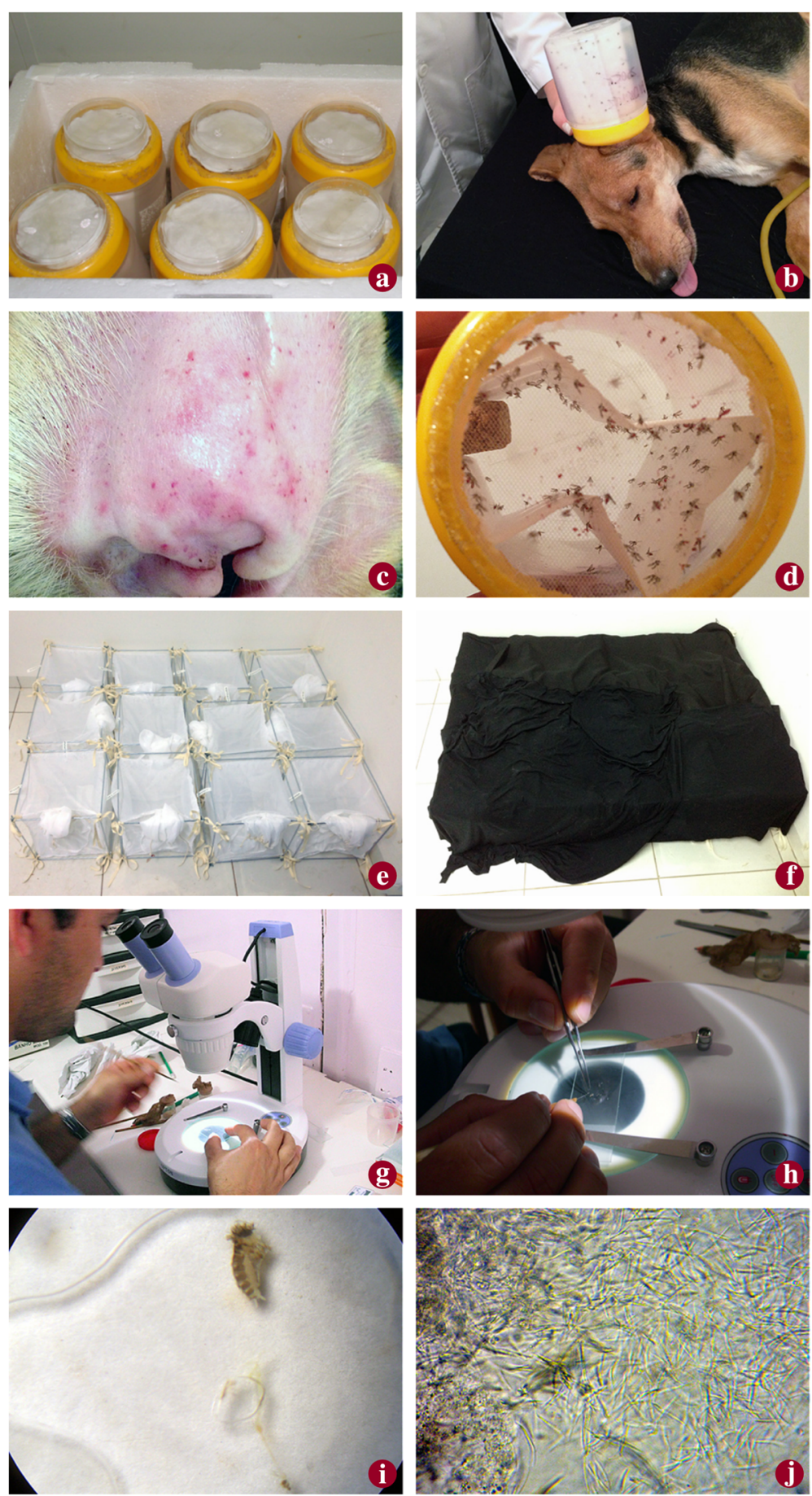

Fig. 1 Method of xenodiagnosis, including use of "phlebocontainers" for transportation (a), placement of a "phlebocontainer" on the dogs ear $(\mathbf{b})$, verification of bites $(\mathbf{c})$, verification of engorgement $(\mathbf{d})$, containment during transformation of the Leishmania in the sand flies (e, $\mathbf{f}$ ), phlebotomine dissection $(\mathbf{g}, \mathbf{h}, \mathbf{i})$ and microscopic visualisation of Leishmania (j)

\section{Data analysis}

The non-parametric Wilcoxon test [38] was used for comparison of averages taken at two evaluation time points.
Repeated measures analysis of variance [39] was used to compare weight, clinical score, parasite load by qPCR and infectivity to sand flies. When the assumption of normality of data was rejected, Friedman's non-parametric test [38] 
was used. The significance level used for the tests was $5 \%$. SPSS 17.0 software for Windows was used for the calculations.

\section{Results}

\section{Variation in dog weights}

During the 12-week period of observation (W0 to W12), the dogs showed a weight gain. Using analysis of variance, a significant change in dog weight throughout the period of evaluation (Repeated measures ANOVA $\left.F_{(6,204)}=7.88, P<0.001\right)$ was found. There was a significant difference in weight loss between W0 and W2 (Repeated measures ANOVA: $F_{(1,34)}=7.85, P=0.008$ ) as well as W0 and W4 (Repeated measures ANOVA contrast W0-W4: $\left.F_{(1,34)}=5.52, P=0.025\right)$. Significantly lower values were obtained for W4 than for W6 (Repeated measures ANOVA contrast W4-W6: $F_{(1,34)}=$ 6.20, $P=0.018$ ), W8 (Repeated measures ANOVA contrast W4-W8: $\left.F_{(1,34)}=11.93, P=0.002\right)$, W10 (Repeated measures ANOVA contrast W4-W10: $F_{(1,34)}=$ 14.04, $P<0.001$ ) and W12 (Repeated measures ANOVA contrast W4-W12: $\left.F_{(1,34)}=17.08, P<0.001\right)$ (Fig. 2).

\section{Clinical evaluation}

The most frequently observed clinical signs before application of the drug were lymphadenopathy (100\%), muscular atrophy (88\%), onychogryphosis (74\%), blepharitis (74\%), localized and/or generalized ulcers (68\%), desquamation (60\%), alopecia (57\%), hyperpigmentation (57\%) and cutaneous nodules (40\%). As shown in Table 2, the average clinical scores reflected a highly heterogeneous group. Before drug administration, $77.14 \%(27 / 35)$ had clinical scores over 10, considered to be very symptomatic. During the observation periods there was a statistically significant decrease (Repeated measures ANOVA: $\left.F_{(6,204)}=69.95, P<0.001\right)$, with a progressive reduction in average scores between weeks W0 $(16.29 \pm 7.57)$ and W2 $(15.26 \pm 7.45)$, W4 (12.14 \pm 5.31), W6 (9.26 \pm 4.45$)$, W8 (7.23 \pm 3.83$)$, W10 (5.46 \pm $3.08)$ and W12 (5.17 \pm 3.12$)$. Dogs showed a reduction in average score from 16.29 to 5.17. Figure 3 shows dogs before treatment (Fig. 3a, c, e, g) and 60 days after the end of treatment (W12) (Fig. 3b, d, f, h). One dog (\#8) with a score of five at W0 and few clinical signs did not show a reduction, but rather an increase at W12 (score of 8).

The repeated measures analysis of variance confirmed that there was a significant change in scores during the evaluation times (Repeated measures ANOVA: $\left.F_{(6,204)}=69.95, P<0.001\right)$. Significantly higher values were observed for W0 than for the other periods (Repeated measures ANOVA contrast W0-W2: $F_{(1,34)}=4.24, P=0.047$; contrast W0-W4: $F_{(1,34)}=38.52, P<0.001$; contrast W0-W6: $F_{(1,34)}=$ 63.56, $P<0.001$; contrast W0-W8: $F_{(1,34)}=88.75, P<$ 0.001; contrast W0-W10: $F_{(1,34)}=88.82, P<0.001$; contrast W0-W12: $\left.F_{(1,34)}=107.02, P<0.001\right)$. Significantly higher values were also observed for W6 than for W12 (Repeated measures ANOVA: $F_{(1,34)}=44.87$, $P<0.001)$.

\section{Skin qPCR}

At W0, an average of 130,988.5 amplified copies was estimated in the qPCR, but six weeks after beginning the treatment (W6) a drastic reduction in parasitic load was detected (99.8\%). At W12, the reduction was $98.7 \%$, as shown in Table 3.

The repeated measures analysis of variance showed a significant change in $\mathrm{QPCR}$ results during the evaluation period (Repeated measures ANOVA: $F_{(2,68)}=$ $15.20, P<0.001)$. Week 0 showed significantly lower values than the other periods (Repeated Measures

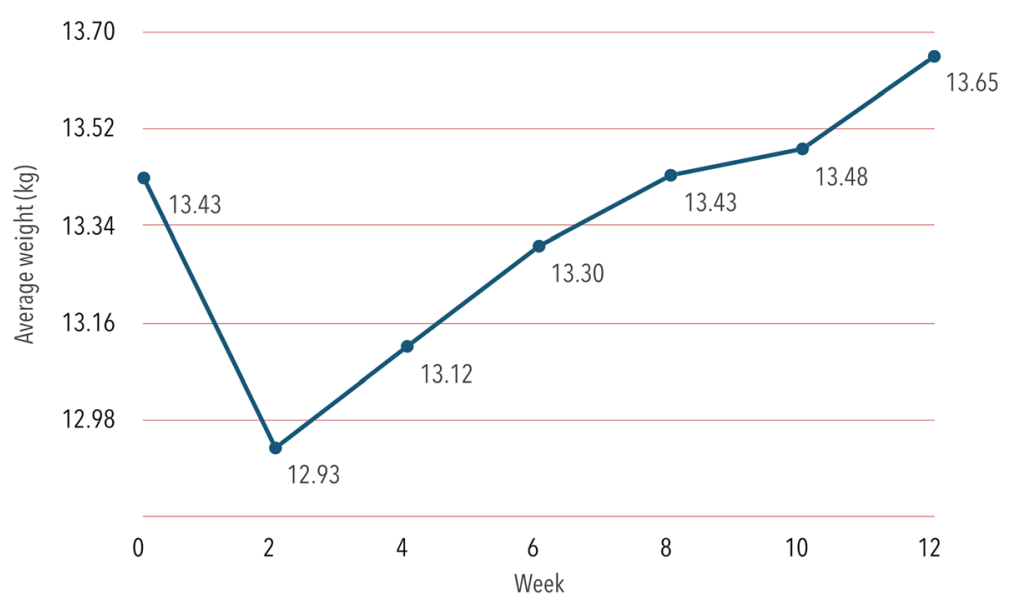

Fig. 2 Average dog weight during 12 weeks of observation 
Table 2 Percent reduction in clinical scores during treatment

\begin{tabular}{|c|c|c|c|c|}
\hline \multirow[t]{2}{*}{ Dog ID } & \multicolumn{3}{|l|}{ Score } & \multirow{2}{*}{$\begin{array}{l}\% \text { reduction } \\
\text { Wo-W12 }\end{array}$} \\
\hline & WO & W6 & W12 & \\
\hline 1 & 17 & 12 & 5 & 70.59 \\
\hline 2 & 19 & 15 & 10 & 47.37 \\
\hline 3 & 17 & 6 & 4 & 76.47 \\
\hline 4 & 17 & 12 & 4 & 76.47 \\
\hline 5 & 14 & 7 & 4 & 71.43 \\
\hline 6 & 11 & 7 & 3 & 72.73 \\
\hline 7 & 21 & 4 & 5 & 76.19 \\
\hline 8 & 5 & 9 & 8 & -60.00 \\
\hline 9 & 13 & 13 & 4 & 69.23 \\
\hline 10 & 27 & 14 & 6 & 77.78 \\
\hline 11 & 7 & 3 & 5 & 28.57 \\
\hline 12 & 15 & 8 & 2 & 86.67 \\
\hline 13 & 14 & 4 & 6 & 57.14 \\
\hline 14 & 16 & 11 & 4 & 75.00 \\
\hline 15 & 24 & 16 & 7 & 70.83 \\
\hline 16 & 17 & 9 & 6 & 64.71 \\
\hline 17 & 21 & 11 & 5 & 76.19 \\
\hline 18 & 21 & 11 & 3 & 85.71 \\
\hline 19 & 11 & 5 & 2 & 81.82 \\
\hline 20 & 21 & 11 & 8 & 61.90 \\
\hline 21 & 13 & 6 & 4 & 69.23 \\
\hline 22 & 27 & 21 & 15 & 44.44 \\
\hline 23 & 9 & 5 & 3 & 66.67 \\
\hline 24 & 4 & 4 & 4 & 0.00 \\
\hline 25 & 23 & 10 & 13 & 43.48 \\
\hline 26 & 27 & 14 & 3 & 88.89 \\
\hline 27 & 8 & 8 & 2 & 75.00 \\
\hline 28 & 30 & 13 & 9 & 70.00 \\
\hline 29 & 11 & 7 & 1 & 90.91 \\
\hline 30 & 31 & 17 & 7 & 77.42 \\
\hline 31 & 10 & 8 & 3 & 70.00 \\
\hline 32 & 9 & 1 & 2 & 77.78 \\
\hline 33 & 3 & 4 & 2 & 33.33 \\
\hline 34 & 11 & 8 & 4 & 63.64 \\
\hline 35 & 26 & 10 & 8 & 69.23 \\
\hline Minimum & 3 & 1 & 1 & \\
\hline Maximum & 32 & 21 & 15 & \\
\hline Average & 16.29 & 9.26 & 5.17 & 68.26 \\
\hline
\end{tabular}

ANOVA contrast W0-W6: $F_{(1,34)}=19.32, P<0.001$; contrast W0-W12: $\left.F_{(1,34)}=17.01, P<0.001\right)$ and W6 did not show any difference in comparison to W12 (Repeated measures ANOVA contrast W6-W12: $F_{(1,34)}$ $=0.84, P=0.366$ ).

\section{Xenodiagnosis}

In the xenodiagnosis at W0, 785 female sand flies, with an average of 22.4 females per dog, were dissected. Leishmania promastigotes were detected in 82 of them (Fig. 1j). Of the 35 dogs included in the study, 18 were infective to the sand flies at W0. At W12 only 9 dogs were infective to the sand flies. At the end of the observation period, $74.29 \%$ of the dogs were negative and/or remained non-infective (Table 4).

\section{Discussion}

In the present study a progressive and statistically significant decrease in clinical scores was observed and verified after administration of miltefosine. Of the 35 dogs evaluated, 33 (94.28\%) showed clinical improvement; the mean score reduction was $68.26 \%$ at week 12 , and only two animals with low scores at week 0 (W0) showed no improvement. The reduction or absence of clinical signs could decrease infectivity to sand flies according to various authors [40-42].

Our results are in accordance with other studies using miltefosine for the treatment of VL sick dogs. Treating naturally infected dogs with only miltefosine [18], a reduction in clinical scores was observed, resulting in a $61.2 \%$ mean on day 56 . Similarly, using a therapy combining miltefosine and allopurinol, Miró et al. [16] observed a significant reduction in clinical scores and parasite load, providing evidence that miltefosine treatment of infected and sick dogs produces a significant clinical improvement in those animals.

Regarding $L$. infantum DNA detection by qPCR, a drastic decrease was observed at six and 12 weeks after initiation of therapy. These results suggest that miltefosine could reduce parasite load in the skin of treated dogs. Duration of the treatment was 28 days and the reduction in parasite DNA occurred at least until week 6 , indicating a continuity of the drug's effect.

The results obtained in our study also demonstrate that qPCR is an important tool for the detection of Leishmania DNA in tissues, mainly in the skin, given its high diagnostic sensitivity, as previously pointed out by other authors [31, 40-43]. It is known that skin is an important tissue in CVL diagnostics because of its high parasitism and as a source of infection [44]. Therefore, these data indicate that the use of qPCR to detect parasite DNA in skin could be an important tool for detection of infected but clinically healthy dogs in endemic areas due to its practicality, accuracy and ease of use.

Regarding the infectiveness of the dogs in our study, the results showed a reduction in the number of dogs that were infective to sand flies. The results reinforce our hypothesis that treated dogs are less infective to sand flies, as previously suggested by other authors [42]. Undoubtedly, the treatment of infected dogs does not 

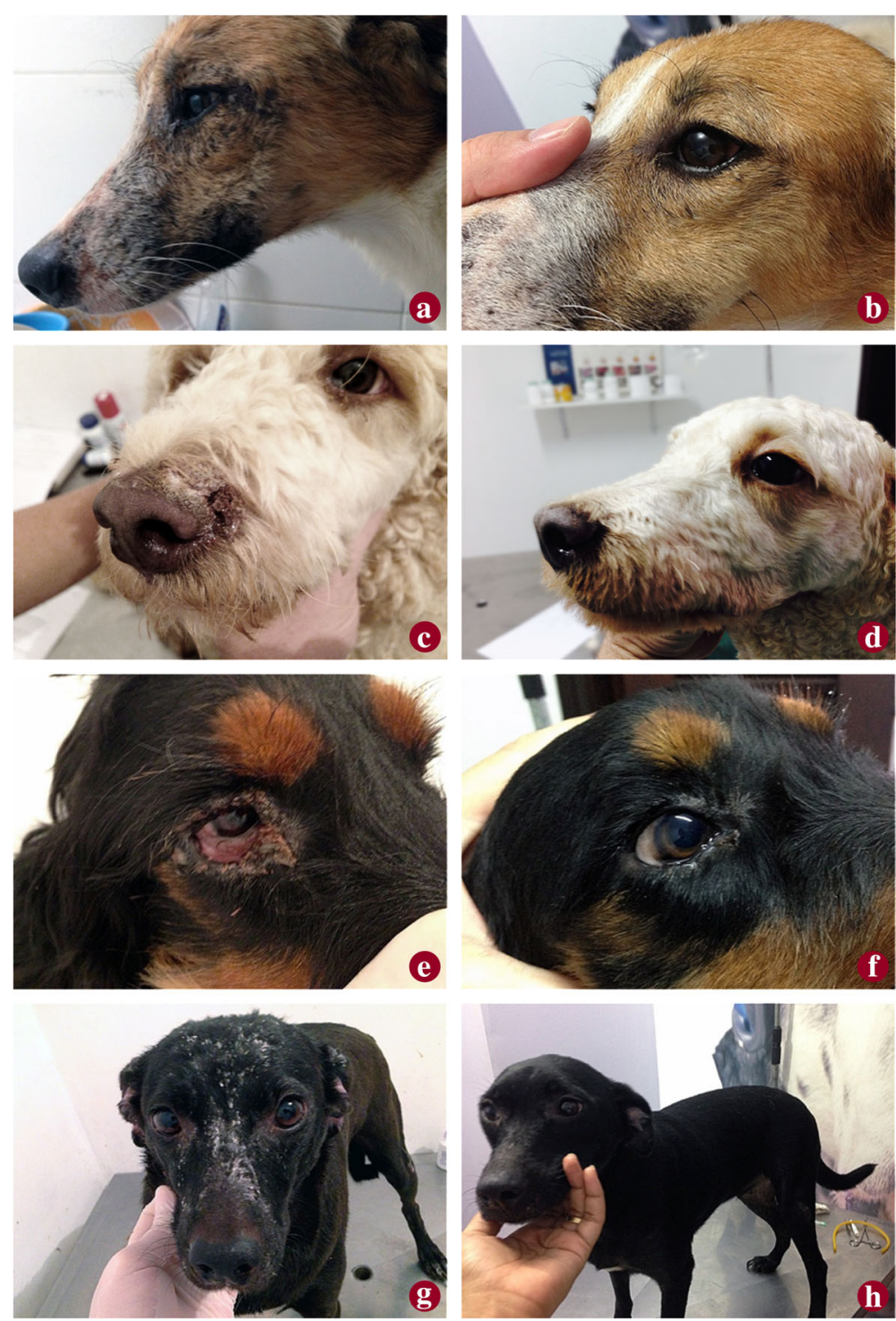

Fig. 3 Dogs before $(\mathbf{a}, \mathbf{c}, \mathbf{e}, \mathbf{g})$ and 60 days after miltefosine treatment (b, $\mathbf{d}, \mathbf{f}, \mathbf{h})$

result in parasitological cure [3, 16, 17, 43, 45]; however, our results suggest that therapy with miltefosine contributes to a reduction in the infectiveness of treated dogs.

The general improvement observed is supported by the clinical scores and results on parasitic load in the skin obtained by qPCR. Considering the different methods to evaluate the treated dogs (clinical scores, qPCR and xenodiagnosis), the present study observes a similarity between the results of xenodiagnosis and those of qPCR.

Our study demonstrated that the use of miltefosine showed potential for reducing the parasitic load of dogs infected with L. infantum; clinical improvement in the dogs was also observed. These results are in agreement with the observations by Woerly et al. [18], showing a reduction in clinical scores, and the observations of
Andrade et al. [46] observations of the progressive clinical improvement and recovery of 50\% of the dogs during the 24 months of the study, although it was not clear to which of the three treatment groups they belonged.

Our data also proved the safety of miltefosine, considering that none of the dogs experienced vomiting or other adverse reactions to the drug at any time during the study period (28 days). This was similar to results obtained by Miró et al. [16], but different from the observations of Woerly et al. [18] showing that $11.7 \%$ of the dogs had adverse reactions.

The results presented herein demonstrate the potential of miltefosine as an alternative treatment for infected dogs in regions where this drug is not used in humans. It should be pointed out that previous studies 
Table 3 Parasite load (number of amplifications) in skin samples determined by qPCR

\begin{tabular}{|c|c|c|c|c|c|c|}
\hline \multirow[t]{2}{*}{$\overline{D o g}$ ID } & \multicolumn{3}{|c|}{ DNA amplification } & \multicolumn{3}{|c|}{$\log _{10}$} \\
\hline & Wo & W6 & W12 & WO & W6 & W12 \\
\hline 1 & 0 & 0 & 0 & - & - & - \\
\hline 2 & 0 & 3.27 & 0 & - & - & - \\
\hline 3 & 0 & 0 & 0 & - & - & - \\
\hline 4 & 0 & 0 & 0 & - & - & - \\
\hline 5 & 0 & 0 & 0 & - & - & - \\
\hline 6 & 125.73 & 0 & 0 & 2.10 & - & - \\
\hline 7 & 1230.63 & 177.68 & 769.60 & 3.09 & 2.25 & 2.89 \\
\hline 8 & 2.94 & 0 & 0 & 0.47 & - & - \\
\hline 9 & $364,348.05$ & 0 & 1.65 & 5.56 & - & 0.22 \\
\hline 10 & 316.23 & 0 & 0 & 2.50 & - & - \\
\hline 11 & 105.76 & 7.1 & 12.43 & 2.02 & 0.85 & 1.09 \\
\hline 12 & 0 & 0 & 1450.97 & - & - & 3.16 \\
\hline 13 & 1.64 & 0 & 0 & 0.21 & - & - \\
\hline 14 & 225.61 & 0 & 2.17 & 2.35 & - & 0.34 \\
\hline 15 & 67.24 & 0 & 0 & 1.83 & - & - \\
\hline 16 & 2946.06 & 0 & 10.12 & 3.47 & - & 1.01 \\
\hline 17 & 0 & 0 & 0 & - & - & - \\
\hline 18 & $1,685,592.16$ & 343.37 & 93.47 & 6.23 & 2.54 & 1.97 \\
\hline 19 & 263.83 & 3.25 & 132.10 & 2.42 & 0.51 & 2.12 \\
\hline 20 & 3172.71 & 3710.09 & $55,727.02$ & 3.50 & 3.57 & 4.75 \\
\hline 21 & 0 & 0 & 0 & - & - & - \\
\hline 22 & 7658.08 & 465.69 & 454.33 & 3.88 & 2.67 & 2.66 \\
\hline 23 & 26.51 & 0 & 0 & 1.42 & - & - \\
\hline 24 & 0 & 0 & 0 & - & - & - \\
\hline 25 & $42,817.04$ & 0.10 & 421.87 & 4.63 & -1 & 2.63 \\
\hline 26 & $77,468.89$ & 85.37 & 68.35 & 4.89 & 1.93 & 1.83 \\
\hline 27 & 0 & 0 & 0 & - & - & - \\
\hline 28 & $923,985.67$ & 4.48 & 30.50 & 5.97 & 0.65 & 1.48 \\
\hline 29 & 3.80 & 0 & 0 & 0.58 & - & - \\
\hline 30 & 601.13 & 1.31 & 0 & 2.78 & 0.11 & - \\
\hline 31 & 324.14 & 0 & 0 & 2.51 & - & - \\
\hline 32 & 0 & 1.30 & 4.37 & - & 0.11 & 0.64 \\
\hline 33 & 13.50 & 0 & 0 & 1.13 & - & - \\
\hline 34 & 7914.55 & 0 & 0 & 3.90 & - & - \\
\hline 35 & $1,465,383.71$ & 9.63 & 277.19 & 6.17 & 0.98 & 2.44 \\
\hline Average & $130,988.45$ & 137.50 & 1698.75 & 3.07 & 0.43 & 1.95 \\
\hline
\end{tabular}

demonstrated that better results have been obtained with complementary/combined therapies [3, 16, 17, 31, 41, 47]. It is mandatory to carefully observe the treated dogs for the rest of their lives to avoid any possibility of drug resistance.
Table 4 Sand flies dissected and infected with Leishmania spp.

\begin{tabular}{|c|c|c|c|c|}
\hline \multirow[t]{2}{*}{ Dog ID } & \multicolumn{2}{|c|}{ Positive phlebotomines/total dissected } & \multicolumn{2}{|c|}{ Percentage (\%) } \\
\hline & Wo & W12 & Wo & W12 \\
\hline 1 & $0 / 20$ & $0 / 25$ & 0 & 0 \\
\hline 2 & $0 / 40$ & $0 / 25$ & 0 & 0 \\
\hline 3 & $0 / 21$ & $0 / 25$ & 0 & 0 \\
\hline 4 & $0 / 20$ & $0 / 25$ & 0 & 0 \\
\hline 5 & $0 / 26$ & $0 / 25$ & 0 & 0 \\
\hline 6 & $0 / 25$ & $0 / 25$ & 0 & 0 \\
\hline 7 & $2 / 33$ & $0 / 25$ & 6.06 & 0 \\
\hline 8 & $0 / 39$ & $0 / 25$ & 0 & 0 \\
\hline 9 & $3 / 24$ & $1 / 21$ & 12.50 & 4.76 \\
\hline 10 & $1 / 15$ & $0 / 25$ & 6.67 & 0 \\
\hline 11 & $0 / 28$ & $0 / 25$ & 0 & 0 \\
\hline 12 & $0 / 25$ & $1 / 20$ & 0 & 5.00 \\
\hline 13 & $0 / 35$ & $0 / 25$ & 0 & 0 \\
\hline 14 & $3 / 20$ & $0 / 25$ & 15.00 & 0 \\
\hline 15 & $1 / 25$ & $0 / 25$ & 4.00 & 0 \\
\hline 16 & $2 / 16$ & $0 / 25$ & 12.50 & 0 \\
\hline 17 & $0 / 17$ & $0 / 18$ & 0 & 0 \\
\hline 18 & $19 / 20$ & $13 / 20$ & 95.00 & 65.00 \\
\hline 19 & $1 / 20$ & $0 / 25$ & 5.00 & 0 \\
\hline 20 & $0 / 20$ & $14 / 20$ & 0 & 70.00 \\
\hline 21 & $0 / 25$ & $0 / 25$ & 0 & 0 \\
\hline 22 & $3 / 21$ & $5 / 20$ & 14.29 & 25.00 \\
\hline 23 & $1 / 20$ & $0 / 25$ & 5.00 & 0 \\
\hline 24 & $0 / 25$ & $0 / 16$ & 0 & 0 \\
\hline 25 & $1 / 21$ & $5 / 20$ & 4.76 & 25.00 \\
\hline 26 & $13 / 20$ & $7 / 20$ & 65.00 & 35.00 \\
\hline 27 & $0 / 22$ & $0 / 21$ & 0 & 0 \\
\hline 28 & $6 / 10$ & $7 / 20$ & 60.00 & 35.00 \\
\hline 29 & $1 / 20$ & $0 / 25$ & 5.00 & 0 \\
\hline 30 & $0 / 20$ & $0 / 25$ & 0 & 0 \\
\hline 31 & $0 / 11$ & $0 / 15$ & 0 & 0 \\
\hline 32 & $4 / 21$ & $0 / 25$ & 19.05 & 0 \\
\hline 33 & $2 / 20$ & $2 / 20$ & 10.00 & 10.00 \\
\hline 34 & $4 / 20$ & $0 / 25$ & 20.00 & 0 \\
\hline 35 & $15 / 20$ & $0 / 25$ & 75.00 & 0 \\
\hline Total & $82 / 785$ & $55 / 801$ & & \\
\hline
\end{tabular}

Considering that the treatment does not cause parasitological cure in treated dogs, it is important to stress the importance of adopting preventive measures for protection of individuals under treatment [45], such as the use of repellents and insecticides to diminish their contact with the vector, as well as measures of environmental control aimed at reducing the vector population. 


\section{Conclusions}

In conclusion, we observed that the use of miltefosine administered orally for 4 weeks contributed to a clinical improvement and reduction in infectivity of dogs to $L$. infantum. Agreement was observed between clinical scores and results obtained by xenodiagnosis and by skin qPCR. There was a statistically significant reduction in parasite load, as evidenced by qPCR from skin. In addition, xenodiagnosis demonstrated a reduction in infectivity of the dogs to sand flies, during the 90 day observation period. These results contribute by offering an important measure to complement the control programs of visceral leishmaniasis in transmission areas of Brazil.

\section{Abbreviations}

BEPA: Boletim Epidemiológico Paulista; CDC: Center for Disease Control; CVL: Canine visceral leishmaniasis; DPP: Dual path platform; ELISA: Enzymelinked immunosorbent assay; PCR: Polymerase chain reaction; qPCR: Realtime polymerase chain reaction; VL: Visceral leishmaniasis; WHO: World Health Organization

\section{Acknowledgements}

We are grateful to the team of Dr Nelder de Figueiredo Gontijo at the Instituto de Ciencias Biológicas da Universidade Federal de Minas Gerais (UFMG), and especially to César Nonato, for supplying the sand flies; Dr José Eduardo Tolezano for allowing us to perform the serological tests and qPCR at the Instituto Adolfo Lutz in São Paulo; Dr Roberto Hiramoto for performing the serological tests; and Cristina da Silva Meira and Ricardo Gava, members of Dr Vera Lucia Pereira-Chioccola's team, for performing the qPCR. We also want to thank the biologists Mariana Dantas, Cecilia Lavitschka and Dr Andrey Jose de Andrade for their assistance in the xenodiagnosis and the team of Dr Márcio Moreira at the Faculdades Anhembi Morumbi for the cytology. We thank Creusa Maria Roveri Dal'Bó for her statistical analysis.

\section{Funding}

This study was funded by Virbac S.A, the manufacturer of Milteforan.

\section{Availability of data and materials}

Data sets generated and/or analyzed during the present study are not publicly available as they are information owned by Virbac of Brasil Indústria e Comércio Ltda., used for registration of the product by the Ministry of Agriculture, Livestock and Supply and the Ministry of Health in Brazil. It is not permitted to disclose or disseminate them in any form, including, but not limited to oral communication or electronically written or recorded documents, to unauthorized persons without the prior written consent of Virbac.

\section{Authors' contributions}

FSN, IM and VCA conceived the study protocol and coordinated its design. FSN and IM coordinated the study. FSN, IM, FGO and APRL performed the xenodiagnoses. LM contributed with logistic support. MAM coordinated the cytology. VLPC coordinated the GPCR. APRL assisted in the clinical observations. FSN, IM and FGO wrote the manuscript. All authors read and approved the final manuscript.

\section{Ethics approval}

This study was performed according to the guidelines of the Brazilian Society for Laboratory Animal Science and was approved by the institutional review board of the Ethics Committee of the Faculdade de Ciências Agrárias da Fundação Educacional de Andradina at 4th July 2013, protocol number 001/2013 FCAA; and by the Ethics Committee for Animal Experimentation at UNICAMP - Universidade Estadual de Campinas.

\section{Consent for publication}

Not applicable.

\section{Competing interests}

VCA was employee of Virbac during the study period. IM, FSN, FGO, LM, MAM, VLPC and APRL declare that they have no competing interests.

\section{Publisher's Note}

Springer Nature remains neutral with regard to jurisdictional claims in published maps and institutional affiliations.

\section{Author details \\ ${ }^{1}$ Fundação Educacional de Andradina, São Paulo, Andradina, Brazil. ²Departamento de Assuntos Regulatórios e Desenvolvimento da Virbac Brasil, São Paulo, Brazil. ${ }^{3}$ Programa de Pós-Graduação em Saúde Pública, Faculdade de Saúde Pública, Universidade São Paulo, São Paulo, Brazil. ${ }^{4}$ Laboratório de Biologia Molecular de Parasitas e Fungos, Instituto Adolfo Lutz, São Paulo, Brazil. ${ }^{5}$ Faculdade de Medicina Veterinária, Universidade Anhembi Morumbi, São Paulo, Brazil. ${ }^{6}$ Ingrid Menz Self-employed Veterinarian, São Paulo, Campinas, Brazil.}

Received: 7 August 2018 Accepted: 28 January 2019

Published online: 08 February 2019

\section{References}

1. Dantas-Torres F, Brandão-Filho SP. Visceral leishmaniasis in Brazil: revisiting paradigms of epidemiology and control. Rev Inst Med Trop Sao Paulo. 2006;48:151-6.

2. Desjeux P. Leishmaniasis: current situation and new perspectives. Comp Immunol Microbiol Infect Dis. 2004;27:305-18.

3. Nogueira F S. Avaliação clínico-laboratorial de cães naturalmente infectados por leishmaniose visceral, submetidos à terapia com anfotericina B. PhD Thesis, Faculdade De Medicina Veterinária e Zootecnia, Universidade Estadual Paulista, Botucatú; 2007. (https://repositorio.unesp.br/bitstream/ handle/11449/101315/nogueira_fs_dr_botfmvz.pdf?sequence=1).

4. Salomon OD, Feliciangeli MD, Quintana MG, Afonso MMS, Rangel EF. Lutzomyia longipalpis urbanisation and control. Mem Inst Oswaldo Cruz 2015;110:831-46.

5. Romero GA, Boelaert M. Control of visceral leishmaniasis in Latin America a systematic review. PLoS Negl Trop Dis. 2010;4:e584.

6. Bates PA. Transmission of Leishmania metacyclic promastigotes by phlebotomine sand flies. Int J Parasitol. 2007;37:1097-106.

7. Kamhawi S. Phlebotomine sand flies and Leishmania parasites: friends or foes? Trends Parasitol. 2006;22:439-45.

8. Bates PA. Leishmania sand fly interaction: progress and challenges. Curr Opin Microbiol. 2008:11:340-4

9. Quaresma PF, Murta SM, Ferreira Ede C, da Rocha-Lima AC, Xavier AA, Gontijo CM. Molecular diagnosis of canine visceral leishmaniasis: identification of Leishmania species by PCR-RFLP and quantification of parasite DNA by real-time PCR. Acta Trop. 2009:111:289-94.

10. Guarga JL, Lucientes J, Peribáñez MA, Molina R, Gracia MJ, Castillo JA. Experimental infection of Phlebotomus perniciosus and determination of the natural infection rates of Leishmania (L.) infantum in dogs. Acta Trop. 2000; 77:203-7.

11. Alvar J, Molina R, San Andrés M, Tesouro M, Nieto J, Vitutia M, et al. Canine leishmaniasis: clinical, parasitological and entomological follow-up after chemotherapy. Ann Trop Méd Parasitol. 1994;88:371-8.

12. Laurenti MD, Rossi CN, da Matta VL, Tomokane TY, Corbett CE, Secundino NF, Pimenta PF, Marcondes M. Asymptomatic dogs are highly competent to transmit Leishmania (Leishmania) infantum chagasi to the natural vector. Vet Parasitol. 2013:196(3-4):296-300

13. Michalsky EM, Rocha MF, da Rocha Lima AC, França-Silva JC, Pires MQ, Oliveira FS, et al. Infectivity of seropositive dogs showing different clinical forms of leishmaniasis, to Lutzomyia longipalpis phlebotomine sand flies. Vet Parasitol. 2007;147:67-76

14. da Costa-Val AP, Cavalcanti RR, de Figueiredo Gontijo N, Michalick MS, Alexander B, Williams P, Melo MN. Canine visceral leishmaniasis: relationships between clinical status, humoral immune response, haematology and Lutzomyia (Lutzomyia) longipalpis infectivity. Vet J. 2007:174:636-43.

15. Soares MRA, Mendonça IL, Bonfim JM, Rodrigues JA, Werneck GL, Costa HN. Canine visceral leishmaniasis in Teresina, Brazil: relationship between clinical features and infectivity for sand flies. Acta Trop. 2011;117:6-9. 
16. Miró G, Oliva G, Cruz I, Cañavate C, Mortarino M, Vischer C, Biancirdi P. Multicentric controlled clinical study to evaluate effectiveness and safety of miltefosine and allopurinol for canine leishmaniosis. Vet Dermatol. 2009:20:397-404.

17. Silva SM. Avaliação clínica e laboratorial de cães naturalmente infectados por Leishmania (Leishmania) chagasi submetidos a um protocolo terapêutico em clínica veterinária de Belo Horizonte. PhD Thesis, Universidade Federal de Minas Gerais, 2011 (http://www.bibliotecadigital. ufmg.br/dspace/handle/1843/SAGF-765GJ2).

18. Woerly C, Maynard L, Sanquer A, Hyone-Myong E. Clinical efficacy and tolerance of miltefosine in the treatment of canine leishmaniosis. Parasitol Res. 2009;105:463-9.

19. Unger C, Damenz W, Fleer EA, Kim DJ, Breiser A, Hilgard P, et al. Hexadecylphosphocholine, a new ether lipid analogue. Studies on the antineoplastic activity in vitro and in vivo. Acta Oncologica. 1989;28:213-7.

20. Croft SL, Snowdon D, Yardley V. The activities of four anticancer alkyllysophospholipids against Leishmania donovani, Trypanosoma cruzi and Trypanosoma brucei. J Antimicrob Chemother. 1996;38:10417.

21. Le Fichoux Y, Rousseau D, Ferrua B, Ruette S, Lelièvre A, Grousson D, Kubar J. Short- and long-term efficacy of hexadecylphosphocholine against established Leishmania infantum infection in BALB/c Mice. Antimicrob Agents Theraper. 1998;42:3654-8.

22. Eue I, Zeisig R, Arndt D. Alkylphosphocholine-induced production of nitric oxide and tumor necrosis factor alpha by U 937 cells. J Cancer Res Clin Oncol. 1995;121:350-6.

23. Safa O, Parkin SM, Bibby MC. $\|-1$ gene expression in human mammary tumour xenografts after treatment with hexadecylphosphocholine. Biochem Soc Trans. 1997;25:265S.

24. Zeisig R, Eue I, Arndt D. Influence of hexadecylphosphocholine on the release of tumor necrosis factor and nitroxide from peritoneal macrophages in vitro. J Cancer Res Clin Oncol. 1995;121:69-75.

25. Safa O, Parkin SM, Matthew AM, Bibby MC. Morphological and immunological observations on the effects of hexadecylphosphocholine (HPC) in nude mice bearing mt-1 breast cancer xenografts. Anticancer Res. 1997; 17:37-43.

26. Gradoni L, Gramiccia M, Mancianti F, Pieri S. Studies on canine leishmaniasis control. 2. Effectiveness of control measures against canine leishmaniasis in the Isle of Elba, Italy. Trans R Soc Trop Med Hyg. 1998;2:568-71.

27. Camargo-Neves VLF. Bol. Epidemiol. Paul. vol 5 no.58 São Paulo Oct. 2008. Secretaria de Saúde de São Paulo, 2008.

28. Baneth G, Hoffman O, Jaffe CL, Strauss D, Schnur LF, Sandler B, et al. A study of the treatment of canine leishmaniasis with allopurinol: parasitological status, infectivity to sandflies, clinical \& serological progression [abstract]. Crete, Greece: WorldLeish 2, Second World Congress on Leishmaniosis; 2001. p. 40.

29. World Health Organization. Control of leishmaniasis. Tech Rep Ser. 1990;793:158.

30. Manna L, Reale S, Vitale F, Gravino AE. Evidence for a relationship between Leishmania load and clinical manifestations. Res Vet Sci. 2009;87:76-8.

31. Miró G, Galvez R, Fraile C, Descalzo MA, Molina R. Infectivity to Phlebotomus perniciosus of dogs naturally parasitized with Leishmania infantum after different treatments. Parasit Vectors. 2011:4:52.

32. Lwanga SK, Lemeshow S. Sample size determination in health studies: A Practical Manual. Geneva: World Health Organization; 1991.

33. Gomes AH, Ferreira IM, Lima ML, Cunha EA, Garcia AS, Araújo MF, PereiraChioccola VL. PCR identification of Leishmania in diagnosis and control of canine leishmaniasis. Vet Parasitol. 2007;144:234-41.

34. Colombo FA, Pereira-Chioccola VL, Meira CS, Motoie G, Gava R, Hiramoto RM, et al. Performance of a real time PCR for leishmaniasis diagnosis using a L. (L.) infantum hypothetical protein as target in canine samples. Exp Parasitol. 2015;157:156-62.

35. Colombo FA, Odorizzi RM, Laurenti MD, Galati EA, Canavez F, PereiraChioccola VL. Detection of Leishmania (Leishmania) infantum RNA in fleas and ticks collected from naturally infected dogs. Parasitol Res. 2011;109:26774.

36. Bustin SA, Benes V, Garson JA, Hellemans J, Huggett J, Kubista M, et al. The Miqe guidelines: minimum information for publication of quantitative real-time PCR experiments. Clin Chem. 2009:55:611-22.

37. Diniz MM, Ovallos FG, de Castro Gomes CM, de Oliveira Lavitschka C, Galati EA. Host-biting rate and susceptibility of some suspected vectors to Leishmania braziliensis. Parasit Vectors. 2014;7:139.
38. Rosner B. Fundamentals of Biostatistics. 2nd ed. Boston: PWS Publishers; 1986. p. 584.

39. Timm NH. Multivariate Analysis with Applications in Education and Psychology. Monterrey, CA, USA: Brooks/Cole; 1975. p. 687.

40. Travi BL, Tabares CJ, Cadena H, Ferro C, Osorio Y. Canine visceral leishmaniasis in Colombia: relationship between clinical and parasitologic status and infectivity for sand flies. Am J Trop Med Hyg. 2001;64:119-24.

41. Courtenay O, Quinnell RJ, Garcez LM, Shaw JJ, Dye C. Infectiousness in a cohort of Brazilian dogs: why culling fails to control visceral leishmaniasis in areas of high transmission. J Infect Dis. 2002;186:1314-20.

42. Borja LS, Souza OMF, Solcá MS, Bastos IA, Bordoni M, Magalhães JT, et al. Parasite load in the blood and skin of dogs naturally infected by Leishmania infantum is correlated with their capacity to infect sand fly vectors. Vet Parasitol. 2016;229:110-7.

43. Solano-Gallego L, Koutinas A, Miró G, Cardoso L, Pennisi MG, Ferrer L, et al. Directions for the diagnosis, clinical staging, treatment and prevention of canine leishmaniosis. Vet Parasitol. 2009;165:1-18.

44. Reis AB, Martins-Filho A, Teixeira-Carvalho A, Carvalho MG, Mayrink W, França-Silva JC. Parasite density and impaired biochemical/hematological status are associated with severe clinical aspects of canine visceral leishmaniasis. Res Vet Sci. 2006;81:68-75.

45. Travi BL, Cordeiro-da-Silva A, Dantas-Torres F, Miró G. Canine visceral leishmaniasis: diagnosis and management of the reservoir living among us. PLoS Negl Trop Dis. 2018;12:e0006082.

46. Andrade HM, Toledo VP, Pinheiro MB, Guimarães TM, Oliveira NC, Castro JA. Evaluation of miltefosine for the treatment of dogs naturally infected with $L$ infantum (= L. chagasi) in Brazil. Vet Parasitol. 2011;181:83-90.

47. Manna L, Corso R, Galiero G, Cerrone A, Muzj P, Gravino AE. Long-term follow-up of dogs with leishmaniosis treated with meglumine antimoniate plus allopurinol versus miltefosine plus allopurinol. Parasit Vectors. 2015;8:289.

\section{Ready to submit your research? Choose BMC and benefit from:}

- fast, convenient online submission

- thorough peer review by experienced researchers in your field

- rapid publication on acceptance

- support for research data, including large and complex data types

- gold Open Access which fosters wider collaboration and increased citations

- maximum visibility for your research: over $100 \mathrm{M}$ website views per year

At BMC, research is always in progress.

Learn more biomedcentral.com/submissions 